\title{
Simultaneous Bilateral Reconstruction of the Axilla with Posterior Arm Flap in Recurrent Hidradenitis Suppurativa
}

\author{
Kingsly Paul M. ${ }^{1}$ Geley Ete ${ }^{1} \quad$ Felix Cordelia M. J. ${ }^{1} \quad$ Anirudha K. Akamanchi ${ }^{1} \quad$ Shwetha Agarwal ${ }^{1}$ \\ ${ }^{1}$ Department of Plastic Surgery, Christian Medical College, Vellore, \\ Address for correspondence Shwetha Agarwal, MS, MCh, MRCSEd, \\ Department of Plastic Surgery, Christian Medical College, Vellore, \\ Tamil Nadu, 632012, India (e-mail: dr.shwetha.agarwal@gmail.com). \\ Indian J Plast Surg 2022;55:66-69.
}

\begin{abstract}
Introduction Hidradenitis suppurativa (HS) is a chronic inflammatory disease, with the axilla being the most commonly affected site. Radical excision of the involved tissue is a definitive treatment. There are numerous techniques described for the reconstruction of the axilla.

Patients and methods Patients with axillary HS who underwent wide excision and posterior arm flap cover between August 2017 and December 2020 were reviewed.

Results A total of 15 flaps were done in eight patients in the study period. Bilateral radical excision of the disease was done simultaneously in all eight patients with the help of a two-team approach. Reconstruction of the axilla was done with a posterior arm flap bilaterally, except one side in a single patient, wherein the split-thickness skin graft was performed. All flaps settled well without significant complications. On follow-

\section{Keywords}

- Hidradenitis suppurativa

- Radical excision

- Axilla reconstruction

- Posterior arm flap up ranging from 12 to 42 months, one patient complained of disease recurrence on one side. The flap and the donor site had settled well in all patients, causing no significant morbidity.

Conclusion Radical excision of axillary hidradenitis must be considered early on presentation. After wide excision, simultaneous bilateral reconstruction with posterior arm flap is a simple and reliable technique with an excellent patient-reported outcome.
\end{abstract}

\section{Introduction}

Recurrent infection of the axilla with hidradenitis suppurativa (HS) is a debilitating disease. Antibiotics alone are not effective in the treatment of recurrent and advanced disease. ${ }^{1}$

Radical excision of all the involved tissues up to the fascia is mandatory to eliminate the disease definitively. ${ }^{2}$ The resultant defect should be reconstructed with well-vascularized tissue. Simultaneous reconstruction of bilateral axillary defect can be done with the posterior arm flap, which has a robust blood supply. The added advantage is that this

published online February 16, 2022
DOI https://doi.org/ $10.1055 / \mathrm{s}-0041-1740087$ ISSN 0970-0358. technique can be executed without a change in the patient's position.

This study presents our experience of radical excision of HS of bilateral axilla and reconstruction with posterior arm flap.

\section{Patients and Methods}

Patients with HS in the axillary region who underwent reconstruction with posterior arm flap between August 2017

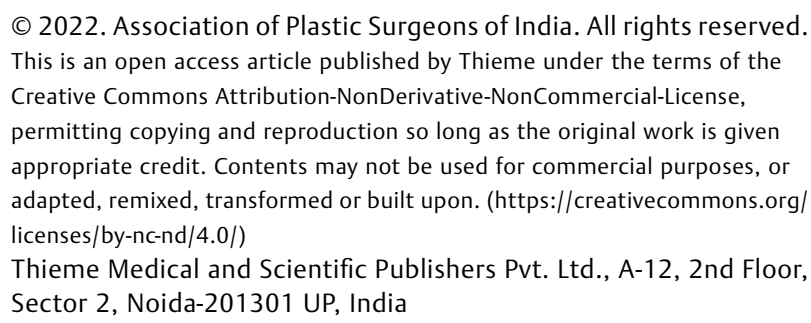


and December 2020 were included in the study. Patient variables including age, gender, body mass index (BMI), duration of complaints, sites involved, and details of previous treatment were recorded. Surgical variables included the size of a defect, length of hospital stay, and complications. On follow-up, recurrence and patient satisfaction were recorded.

\section{Surgical Technique}

General anesthesia was used in all patients. Patients were positioned in a supine posture with both arms abducted and rested on hand tables. The involved tissue was excised radically, with all the unhealthy subcutaneous fat and fibrotic tissue and the sinuses, including the fascia. Most often, the dissection extended till the axillary vein was exposed.

With the arm lifted at $90^{\circ}$ from the table and supported by an assistant, an ellipsoid-shaped posterior arm flap was designed with its long axis connecting the olecranon and the posterior axillary fold. A constant perforator was detected with the help of a handheld Doppler $(8 \mathrm{MHz})$ at 1 to $2 \mathrm{~cm}$ medial to the postaxillary border and 3 to $4 \mathrm{~cm}$ distal to the axillary crease on the arm. Size of the flap may vary depending on the size of the defect, with the farthest length reaching the junction of proximal $2 / 3$ rd and distal $1 / 3$ rd of the arm, while the width depends on skin pinch and ability to close the donor primarily.

Elevation of the flap is straightforward, from distal to proximal, in the subfascial plane up to the marked perforator. The skin and the subcutaneous tissue were incised down through the brachial fascia, including the fascia into the flap. The plane is in between the triceps brachii muscle and the fascia. The pedicle can be seen on the undersurface of the flap, running within the fascia. At this point, either an islanded flap or a flap with a skin bridge would be easily transposed on the defect. Perforator dissection is not mandatory for the flap to reach the defect in the axilla. The donor site was closed primarily after keeping a suction drain.

\section{Results}

A total of 15 posterior arm flaps were done on eight patients in the study period (-Table $\mathbf{1}$ ). HS was seen in bilateral axillae in all our patients, presenting at different stages. Five patients had bilaterally stage III disease. Three patients had a lower stage on one side. Females were affected more commonly than males (3:1). The affected individuals belonged to the age group of 17 to 34 , the mean age being 27.6. Obesity with BMI $>25$ was found in 5 patients. None of the patients were smokers. The duration of symptoms varied from 1.5 years to 17 years. Patients typically had been to multiple centers undergoing different medical treatments. Seven patients had undergone incision and drainage numerous times. Three patients had completed a course of multidrug anti-Kochs treatment started empirically. Extra-axillary involvement was noted in 5 patients.
Bilateral radical excision of the disease was done simultaneously in all eight patients with the help of a two-team approach. Reconstruction of the axilla was done with a posterior arm flap bilaterally, except one side in a single patient where the split-thickness skin graft was performed. There were no significant complications seen in any patient, with only one patient having a minor surgical site infection that healed in a few days with dressings. Length of hospital stays varied from 1 to 8 days. Follow-up of patients ranged from 12 to 42 months. A single patient had a recurrence on one side. The rest were satisfied with the procedure, with complete relief of symptoms and no significant flap or donor morbidity (-Figs. 1 and $\mathbf{2}$ ).

\section{Discussion}

Following wide excision in advanced HS of the axilla, reconstruction is planned routinely with regional flaps or split skin graft. Flaps have a definite advantage over skin grafts, avoiding complications like poor graft take, poor color match, and possible secondary contracture, limiting the range of motion. The flaps described include local transposition flaps such as Limberg flap ${ }^{3}$ or the V-Y advancement flap, ${ }^{4}$ thoracodorsal artery perforator flap, ${ }^{5}$ lateral thoracic flap, ${ }^{6}$ and posterior arm flap. $^{7-9}$

In our experience, a posterior arm flap is a preferred choice, considering its simplicity and reliability. It is based on an unnamed constant artery arising from the brachial artery or the profunda brachii artery through the triceps muscle aponeurosis at the termination of the tendon of teres major. Initially, it was described as a free flap by Masquelet et al. ${ }^{10}$ Later, pedicled posterior arm flap was used in axillary reconstruction after excision in severe $\mathrm{HS}^{7,8}$ and axillary burn contractures. ${ }^{11}$ It is used with a skin bridge at the base or an islanded flap in axilla reconstruction. The constant robust vascularity explains the low incidence of complications in these patients, corroborated in all studies. ${ }^{12-14}$ It is a consistently reliable flap with no instances of flap ischemia or partial or complete flap failure. Donor-site morbidity was only in the form of a linear scar in the back of the arm, which was accepted readily in our patients because of the brachioplasty effect seen simultaneously on both arms. ${ }^{15}$ The color and contour match is acceptable, with no secondary procedures needed in most patients.

In bilateral cases, Sirvan et al preferred to operate the less affected side after there was complete healing on another side. ${ }^{8}$ Similarly, Thomson et al also preferred a second procedure for the contralateral side. ${ }^{9}$ We routinely followed a two-team approach with simultaneous bilateral axillary wide excision and posterior arm flap cover in our patients. We preferred a single-staged procedure with the help of a two-team approach, since the time taken for surgery was reduced, with the need for second general anesthesia avoided. It is also cost-effective for the patients. We routinely offer early surgical intervention irrespective of previous medical treatment in chronic/recurrent HS. 


\begin{tabular}{|c|c|c|c|c|c|c|c|c|}
\hline 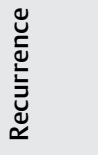 & 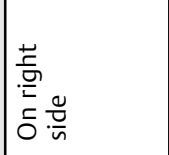 & $\overline{\bar{z}}$ & $\overline{\bar{z}}$ & $\overline{\bar{z}}$ & $\overline{\bar{z}}$ & $\overline{\bar{z}}$ & $\overline{\bar{z}}$ & $\overline{\bar{z}}$ \\
\hline 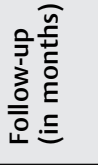 & $\mathscr{F}$ & mे & $m$ & ळे & $\stackrel{\infty}{\sim}$ & $\stackrel{\Xi}{\sim}$ & $\ddot{\sim}$ & $\simeq$ \\
\hline 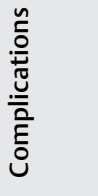 & $\overline{\bar{z}}$ & 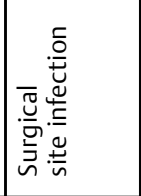 & $\overline{\bar{z}}$ & $\overline{\bar{z}}$ & $\overline{\bar{z}}$ & $\overline{\bar{z}}$ & $\overline{\bar{z}}$ & $\overline{\bar{z}}$ \\
\hline 吕 & $\sim$ & $\infty$ & 0 & $\wedge$ & $\infty$ & - & - & $\infty$ \\
\hline$\frac{\check{n}}{\frac{\pi}{L}}$ & 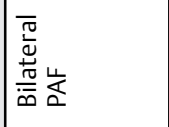 & 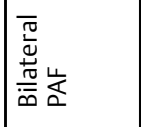 & 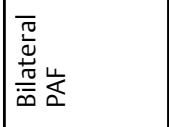 & 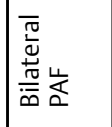 & 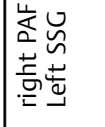 & 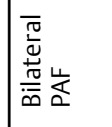 & 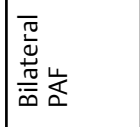 & 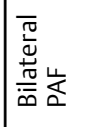 \\
\hline 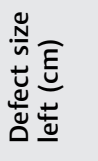 & $\begin{array}{l}x \\
x \\
a\end{array}$ & $\begin{array}{l}\infty \\
x \\
m \\
-\end{array}$ & $\mid \begin{array}{r}\hat{x} \\
\simeq\end{array}$ & $\begin{array}{l}0 \\
\times \\
a\end{array}$ & 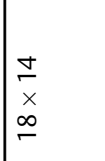 & $\begin{array}{l}\text { In } \\
\times \\
\infty \\
\end{array}$ & $\begin{array}{l}x \\
x \\
\dot{t}\end{array}$ & $\begin{array}{l}0 \\
\times \\
\infty\end{array}$ \\
\hline 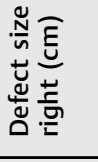 & $\begin{array}{l}0 \\
\times \\
a\end{array}$ & $\begin{array}{l}\infty \\
x \\
x \\
\pm\end{array}$ & \begin{tabular}{l}
0 \\
$\times$ \\
$\circ$ \\
\hdashline
\end{tabular} & $\mid \begin{array}{l}x \\
x \\
\circ\end{array}$ & \begin{tabular}{|l|l}
$n$ \\
$x$ \\
$\infty$
\end{tabular} & $\begin{array}{l}n \\
x \\
\infty \\
\infty\end{array}$ & $\begin{array}{l}0 \\
x \\
0 \\
0\end{array}$ & $\begin{array}{l}n \\
x \\
\sigma\end{array}$ \\
\hline 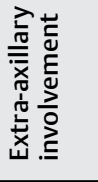 & & 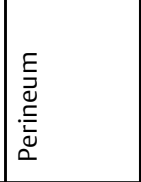 & 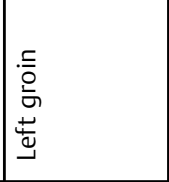 & 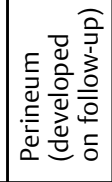 & 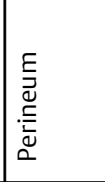 & & & 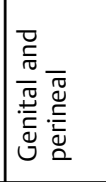 \\
\hline 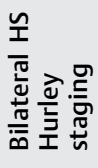 & 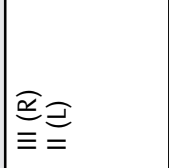 & $\begin{array}{l}\hat{\underline{\alpha}} \mathcal{E} \\
\equiv=\end{array}$ & 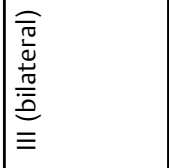 & 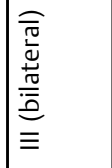 & 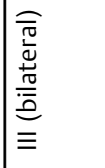 & $\begin{array}{l}\widehat{\underline{\underline{\alpha}}} \overline{\underline{a}} \\
=\equiv\end{array}$ & 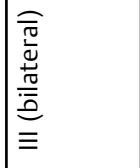 & 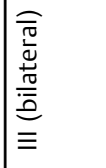 \\
\hline 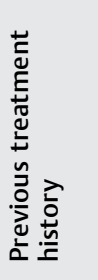 & 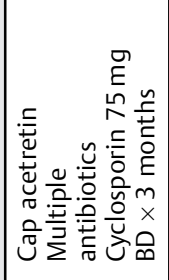 & 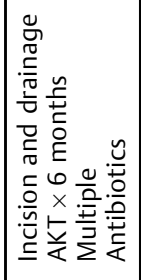 & 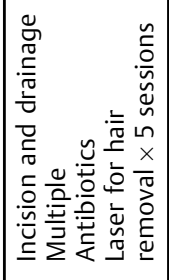 & 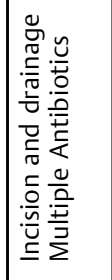 & 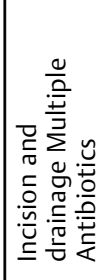 & 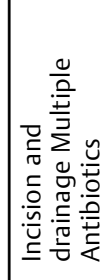 & 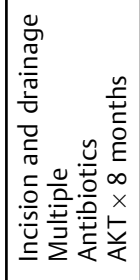 & 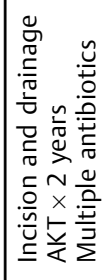 \\
\hline 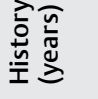 & $\stackrel{\stackrel{2}{2}}{\longrightarrow}$ & $\sim$ & $\approx$ & 0 & $\sim$ & $m$ & 0 & $\stackrel{\circ}{\circ}$ \\
\hline$\sum_{\infty}$ & $\stackrel{m}{\stackrel{m}{N}}$ & 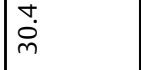 & $\stackrel{\stackrel{\dot{\sim}}{\sim}}{ }$ & $\bar{\sigma}$ & ڤั. & 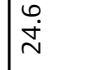 & $\mid \begin{array}{l}\infty \\
\stackrel{\infty}{~}\end{array}$ & ळิ \\
\hline 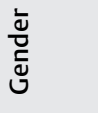 & 4 & $\sqcup$ & $\sqcup$ & 4 & $\Sigma$ & $\Sigma$ & 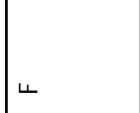 & 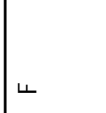 \\
\hline 芩 & $\bar{m}$ & $\approx$ & $m$ & $\approx$ & $\stackrel{\Perp}{\sim}$ & m & 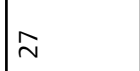 & $\tilde{m}$ \\
\hline 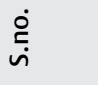 & - & $\sim$ & $m$ & $\nabla$ & in & 0 & $\wedge$ & $\infty$ \\
\hline
\end{tabular}




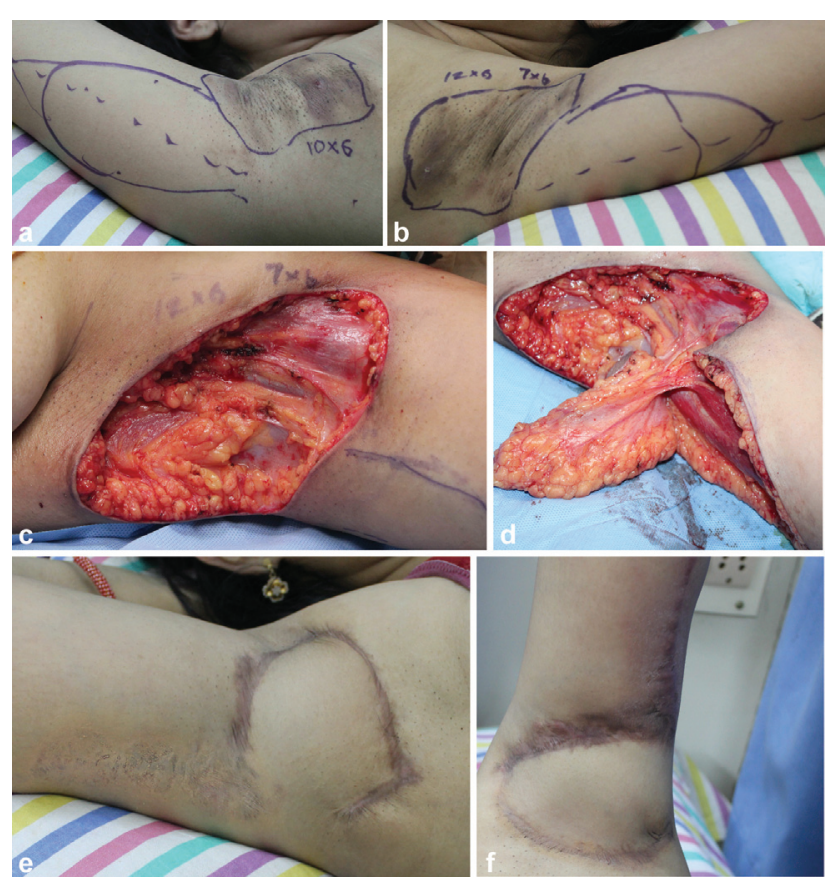

Fig. 1 Patient 3: 33-year-old female with 17-year history of bilateral disease. ( $\mathbf{a}$ and $\mathbf{b})=$ preoperative with flap marking (right and left). (c) = intraoperative defect (left side). (d) = elevated and transposed flap with pedicle visualized (left side). (e and $\mathbf{f})=$ postoperative.
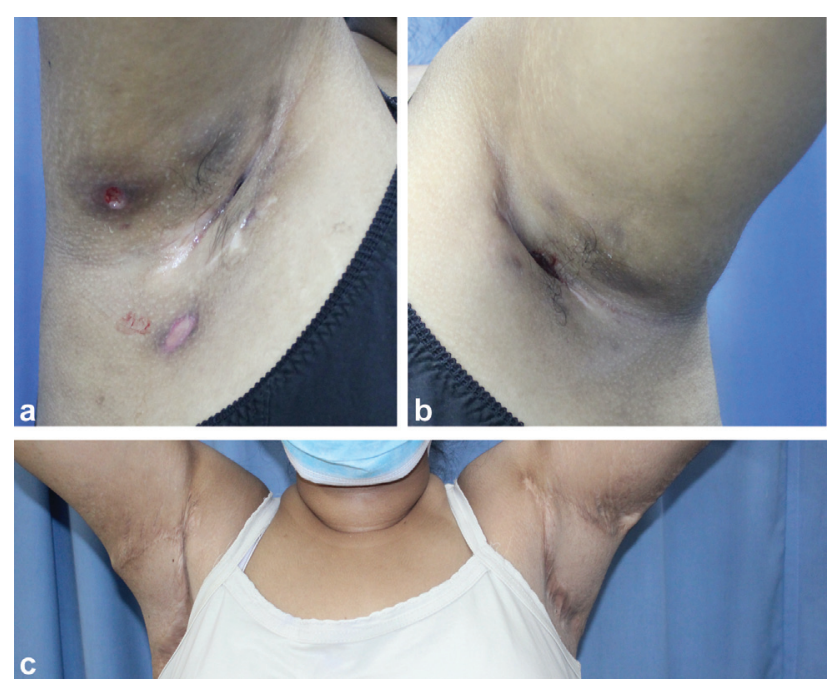

Fig. 2 Patient 2: 17-year-old female with 2-year history of bilateral disease. $(\mathbf{a}$ and $\mathbf{b})=$ preoperative. $(\mathbf{c})=$ postoperative.

\section{Conclusion}

Radical excision of HS of the axilla must be considered early on presentation, since this is definitive treatment. Simultaneous reconstruction of the bilateral axilla with posterior arm flap is a simple and reliable technique, with an excellent patient-reported outcome.

\section{Contributions}

K.P., G.E. and S.A. were the operating surgeons. K.P. and G. E. conceptualized the manuscript. G.E. and S.A. wrote the manuscript. A.A. and F.C. compiled data and results. All authors read and approved the final version of the manuscript.

\section{Statement of IRB approval}

Approval of Institutional review board was taken before submitting the study.

\section{Conflict of Interest \\ None declared}

\section{References}

1 Alikhan A, Lynch PJ, Eisen DB. Hidradenitis suppurativa: a comprehensive review. J Am Acad Dermatol 2009;60(04):539-561, quiz 562-563

2 Rompel R, Petres J. Long-term results of wide surgical excision in 106 patients with hidradenitis suppurativa. Dermatol Surg 2000; 26(07):638-643

3 O'Brien J, Wysocki J, Anastasi G. Limberg flap coverage for axillary defects resulting from excision of hidradenitis suppurativa. Plast Reconstr Surg 1976;58(03):354-358

4 Sharma RK, Kapoor KM, Singh G. Reconstruction in extensive axillary Hidradenitis suppurativa with local fasciocutaneous V-Y advancement flaps. Indian J Plast Surg $\cdots ; 39(01)$ :

5 Wormald JCR, Balzano A, Clibbon JJ, Figus A. Surgical treatment of severe hidradenitis suppurativa of the axilla: thoracodorsal artery perforator (TDAP) flap versus split skin graft. J Plast Reconstr Aesthet Surg 2014;67(08):1118-1124

6 Teo W-L, Ong Y-S, Tan B-K. Radical surgical excision and use of lateral thoracic flap for intractable axillary hidradenitis suppurativa. Arch Plast Surg 2012;39(06):663-666

7 Elliot D, Kangesu L, Bainbridge C, Venkataramakrishnan V. Reconstruction of the axilla with a posterior arm fasciocutaneous flap. Br J Plast Surg 1992;45(02):101-104

8 Sirvan SS, Demir IA, Irmak F, et al. Posterior arm perforator flap for axillary reconstruction after hidradenitis suppurativa excision. Plast Surg (Oakv) 2019;27(03):204-210

9 Thomson DR, Saltrese S, Mehdi S. Modified posterior arm flap for axillary hidradenitis suppurativa. Ann Plast Surg 2021 (e-pub ahead of print). Doi: 10.1097/SAP.0000000000002819

10 Masquelet AC, Rinaldi S. Anatomical basis of the posterior brachial skin flap. Anat Clin 1985;7(03):155-160

11 Guha G, Agarwal AK, Gupta S, et al. Posterior arm flap in management of axillary contracture. Burns 2013;39(05): 972-977

12 Costa MLR, Azevedo L, Zenha H, Pinto A, Costa H. The posterior arm flap-our department's experience. Eur J Plast Surg 2011;34 (02):119-124

13 Hodgins N, Bhat W, Pape SA. The posterior arm flap in reconstruction of axillary defects: A lifeboat when soft tissue cover is limited. J Plast Reconstr Aesthet Surg 2015;68(11): 1629-1631

14 Schmidt M, Dunst-Huemer KM, Lazzeri D, Schoeffl H, Huemer GM. The versatility of the islanded posterior arm flap for regional reconstruction around the axilla. J Plast Reconstr Aesthet Surg 2015;68(07):953-959

15 Huemer GM. Some thoughts on the posterior brachioplasty. Plast Reconstr Surg 2011;127(06):2516-2517 